\title{
Lubricities of Environmentally Acceptable Lubricants with Zinc Dialkyldithiophosphate and Dibenzyl Disulfide on Tribological Properties of Plasma Electrolytic Oxidation Coated A6061-T6 Alloy under Mixed/Boundary Lubrication
}

\author{
Takuya Nakase ${ }^{1,3)^{*}}$, Shinji Kato ${ }^{1)}$, Mathias Woydt ${ }^{2)}$ and Shinya Sasaki ${ }^{3)}$ \\ ${ }^{1)}$ Material Engineering Section, Basic Technology R\&D Center, KYB Corporation, Japan \\ 1-12-1 Asamizodai, Minami-ku, Sagamihara-shi, Kanagawa-ken, 252-0328, Japan \\ ${ }^{2)}$ Division 6.3: Macro-Tribology and Wear Protection, Federal Institute for Material Research and Testing (BAM) \\ Unter den Eichen 87, 12489 Berlin, Germany \\ ${ }^{3)}$ Department of Mechanical Engineering, Tokyo University of Science \\ 6-3-1 Niijuku, Katsushika-ku, Tokyo, 125-8585, Japan \\ *Corresponding author: nakase-tak@kyb.co.jp
}

( Manuscript received 24 October 2014; accepted 24 December 2014; published 28 February 2015 )

3 different base-stocks (poly- $\alpha$-olefin, polypropylene glycol and unsaturated TMP ester) and additionally formulations with 2 different additives ( 1 mass $\%$ ZnDTP or 1 mass $\%$ dibenzyl disulfide (DBDS)) were used as lubricants to evaluate the tribological properties of A6061-T6 treated by means of plasma electrolytic oxidation in a SRV tribometer $\left(T_{\text {oil }}=80^{\circ} \mathrm{C}, F_{\mathrm{N}}=50 \mathrm{~N}, v=50 \mathrm{~Hz}, 2 \mathrm{~mm}\right.$ stroke, $\left.2 \mathrm{hrs}\right)$. The base oils of PPG and the TMP-ester had better lubricities than the PAO with/without the additives. ZnDTP tend to reduce wear, but when added to PAO and PPG increased the friction. The unsaturated TMP-ester +1 mass $\%$ DBDS showed 45\% lower friction than PAO + ZnDTP (reference), whereas PPG + DBDS had 30\% lower friction.

Keywords: polyglycol, ester, aluminium alloy, plasma electrolytic oxidation coating, friction, wear

\section{Introduction}

Hydraulic fluids/lubricants are an element of mechanical parts and they are composed of base oil and various additives. The lubricating mechanisms have been studied for many decades mainly for frequent materials used in industries such as steel and cast iron. A well known anti-wear additive is zinc dialkyldithiophosphate (ZnDTP), which most effectively prevent wear on sliding parts [1]. Recently, due to the environmental issues low-toxic organic additives are used for environmentally acceptable lubricants (EALs) or environmentally considerable lubricants (ECLs) to develop new lubricant technologies $[2,3]$. In order to meet the environmental criteria, esters are commonly used as base oils, which are good biodegradable and less toxic. Polyalkylen glycols (PAGs) are also used in specific applications and meet the eco-tox criteria. Appropriate molecular design (i.e. high polarity) of PAG would have excellent performance [4].

In mechanical parts various materials such as steel, aluminium alloys, titanium alloys, polymers and their composite materials, etc. are used. Except for steel, aluminium alloys are most commonly applied light-weight material, which possesses excellent mechanical and physical properties for machine parts. However, the application of aluminium alloys is limited due to the poor wear resistance. Furthermore, aluminium alloy may cause severe corrosive wear when it is lubricated with polar compounds such as polyester and polyglycol which are used for EAL's base stock. It was reported that 10 times higher wear rate was found on aluminium material compared with hydrocarbon-based/ mineral-based oil [5,6]. The corrosion and wear resistance of aluminium can be improved by converting the surface through an anodic oxidation. Anodized aluminium alloys are widely used for mechanical parts such as for automotive engine and hydraulics, which used either oxalic or sulfuric acid. The interaction of additives and base oils on conversion coatings of aluminium are less explored, except for lubrication of steel alloys. For further high wear resistance, the novel plasma electrolytic oxidation (PEO) represents an additional option. The surface of $\mathrm{PEO}$ coated aluminium 


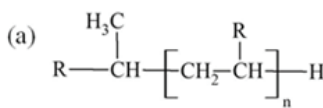

(b) $\mathrm{H}_{3} \mathrm{C}-\left(\mathrm{CH}_{2}\right)_{3}\left[\mathrm{O}-\stackrel{\mathrm{CH}_{2}}{\mathrm{C}} \mathrm{CH}_{3}\right]_{\mathrm{n}}-\mathrm{OH}$

(c)
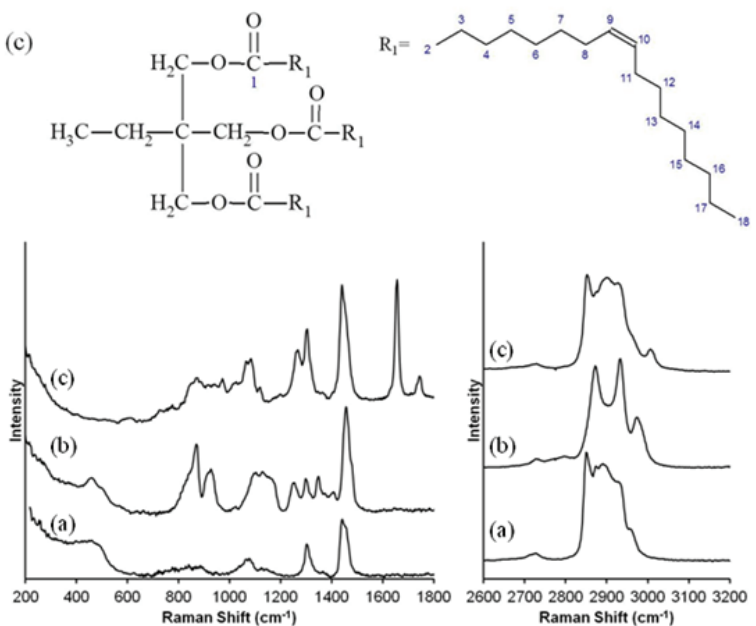

Fig. 1 Chemical structures and Raman spectra of base oils: (a) poly-alpha-olefine (PAO), (b) polypropylene glycol (PPG) and (c) trimethylolpropane (TMP) unsaturated ester

alloy can increase surface hardness up to $2000 \mathrm{HV}$ [7] by forming a dense nano-crystalline alumina-type ceramic film. In general, alumina is chemically stable under static condition, whereas it might be able to interact with oil when tribological action is applied [8].

The aim of the present study was to investigate influence of ZnDTP and DBDS in combination with EAL's on aluminium based alloys to find out candidates for high loaded sliding parts under boundary lubricating condition. In this paper, the effect of blended oils with typical anti-wear additives on tribological properties of PEO coating will be discussed.

\section{Experimental}

\subsection{Lubricants}

A poly-alpha-olefin (PAO), a polypropylene glycol (PPG, n-butanol initiated) and a trimethylolpropane ester of oleic acid (unsaturated TMP or TMP oleate) were selected as base oils for test formulations used in this study. Since PAO is the most major base stock among synthetic oil, it was selected as reference lubricant in this study. PAO is similar to mineral oil but synthesized into more "pure" product. Furthermore PAO is a non-polar base stock due to its chemical structure based on hydrocarbons. PPG and TMP ester are selected as most common EAL base stocks having same viscosity grade as PAO. They have high biodegradability of over $80 \%$. The typical chemical structures are shown in Fig. 1 with their Raman-spectra and some physical properties in Table 1. Esters and polyglycols contain molecular oxygen. TMP ester has three ester bonds (-COO- in triesters), which are located mainly in the center of the molecule. In contrast, polyglycols have an "ether" link (C-O-C), e.g., an oxygen polarity, in each monomer of the whole backbone. Consequently, it is likely that the polarities of the ionic bonds of the alumina will interact with the highly polar part of oxygenates in the backbones of the esters and polyglycols. In order to investigate the effect of additives, a widely used AW additive, zinc dialkyldithiophosphate (ZnDTP, [4259-15-8]), and an organic sulfur containing additive, dibenzyl disulfide (DBDS, [150-60-7]), were selected and blended each by 1 mass $\%$ into the three base oils to make 6 different test formulations.

\subsection{Plasma electrolytic oxidation (PEO) coating}

To prevent corrosive wear on aluminium alloy, an adaption of surface protecting coatings on the substrate was considered. In this study, the target of wear rate on aluminium alloy was $1 \times 10^{-8} \mathrm{~mm}^{3} / \mathrm{Nm}$ as same as in steel-steel sliding system. Conventional anodizing forms amorphous alumina on aluminium surface. However, since the hardness of the anodic film (up to $450 \mathrm{HV}$ ) is lower than hardened steel surface (approximately 800 $\mathrm{HV}$ ), the wear rate of the anodized aluminium alloy could not meet same results like steel. Therefore, plasma electrolytic oxidation coating (PEO) was selected which is harder (up to $2000 \mathrm{HV}$ ) and expected to reduce wear and more stable in the adsorptive polar lubricants such mentioned above. PEO was deposited on A6061-T6 $(\mathrm{AlMg} 1 \mathrm{SiCu})$ by Keronite International Ltd. The thickness of the coating was approximately $45 \mu \mathrm{m}$ in as-deposited film, approximately $32 \mu \mathrm{m}$ in polished disks. The polished disks were used for tribological tests. The surface roughness of the coating is listed in Table 2.

\subsection{Friction and wear evaluation}

Oscillating sliding tests were performed to evaluate friction and wear behavior, according to DIN 51834-4 (roller on disk). The test conditions are listed in Table 3. Specimens were ultrasonically cleaned with petroleum

Table 1 Lubricants and their physical properties

\begin{tabular}{lccc}
\hline Base oil & $\begin{array}{c}\text { Density } 15^{\circ} \mathrm{C} \\
\left(\mathrm{g} / \mathrm{cm}^{3}\right)\end{array}$ & $\begin{array}{c}\text { Viscosity } 40^{\circ} \mathrm{C} \\
(\mathrm{cSt})\end{array}$ & Viscosity index \\
\hline PAO & 0.833 & 48.0 & 139 \\
PPG & 0.994 & 47.5 & 167 \\
TMP us. & 0.920 & 46.0 & 192 \\
\hline
\end{tabular}


Table 2 Plasma electrolytic oxidation coating

\begin{tabular}{llccc}
\hline Coating & Description & $\begin{array}{c}\text { Hardness } \\
\mathrm{GPa}^{* *}\end{array}$ & $\begin{array}{c}\text { Thickness } \\
\mu \mathrm{m}\end{array}$ & $\begin{array}{c}\text { Roughness }[\mu \mathrm{m}] \\
R_{\mathrm{a}}, R_{\mathrm{pk}}, R_{\mathrm{vk}}\end{array}$ \\
\hline PEO & $\begin{array}{l}15 \% \text { alpha }+ \text { gamma(eta) } \\
\text { alumina }{ }^{*}, \text { polished }\end{array}$ & 6.9 & 32 & $0.30,0.17,0.69$ \\
& & & \\
${ }^{*}$ Characterization from XRD; ${ }^{* *}$ Universal hardness by nanoindenter (Fischerscope, $1000 \mathrm{mN}$ )
\end{tabular}

spirit shortly before testing. A roller made of SAE E52100 (100Cr6) was fixed in a holder, where the roller was deflected by $10^{\circ}$ to the oscillating direction (Fig. 2). Longitudinal sliding direction can provide more stable oil film formation rather than transvers sliding direction. Because the former can let the lubricant to flow along the roller, while the latter can squeezing lubricant out from contact. The $10^{\circ}$ deflection contributes to alleviate the moment of rotation of the roller preventing wobbling. Thus much precise result can be obtained rather than in case of parallel sliding motion. Disk was made of A6061-T6 aluminium alloy coated by the PEO coating. Lubricant was dropped onto lower disk specimen and had meniscus at the edge of the roller. The normal load was controlled by electric motor. The averaged coefficient of friction (COF), maximum COF and several friction hysteresis were recorded during the test by a digital data acquisition system. The averaged COF was calculated by the following formula:

$$
C O F_{\mathrm{avg}}=K /\left(\Delta X \cdot F_{\mathrm{N}}\right)
$$

Hereby, $C O F_{\text {avg }}$ is the averaged $\mathrm{COF}, K$ is friction energy $[\mathrm{Nmm}]$ that is equivalent to the area of friction hysteresis (one forward- and backward movement), $\Delta X$ is the stroke and $F_{\mathrm{N}}$ is the normal load.

After the test both upper and lower specimens were cleaned with the solvent. The wear scar on the roller was measured with an optical microscope and the disk with a profilometer.

\section{Results and discussion}

\subsection{Wear}

Fig. 3 shows the result of wear evaluation by the standard inclined roller SRV test in steel/PEO lubricated with the aforementioned oils. The wear rates of roller were in the order of $10^{-7} \mathrm{~mm}^{3} / \mathrm{N} \cdot \mathrm{m}$. The lowest wear rate

Table 3 Test conditions

\begin{tabular}{lc}
\hline Normal load $(\mathrm{N})$ & 50 \\
Frequency $(\mathrm{Hz})$ & 50 \\
Stroke $(\mathrm{mm})$ & 2 \\
Mean sliding speed $(\mathrm{m} / \mathrm{s})$ & 0.2 \\
Temperature $\left({ }^{\circ} \mathrm{C}\right)$ & 80 \\
Test duration $(\mathrm{min})$ & 120 \\
Sliding distance $(\mathrm{m})$ & 1440 \\
\hline
\end{tabular}

on roller was obtained, when PAO was blended with ZnDTP. PPG base oil also showed comparatively low wear on roller. DBDS tends to increase in all base oils the wear on roller.

The wear on the PEO disk was very low regardless of the lubricant type, especially extremely low wear rates of less than $10^{-8} \mathrm{~mm}^{3} / \mathrm{N} \cdot \mathrm{m}$ were obtained for unsaturated TMP ester. ZnDTP and DBDS had wear reduction effect on PEO but not on the counter steel.

\subsection{Friction behavior}

Friction behavior was much more influenced by the additive addition. Figures 4-6 show COF as function of sliding time for PAO, PPG and TMP blended oils, respectively. The COF of PAO base oil was initially approximately at 0.11 and slightly increased by sliding time. ZnDTP increased friction for PAO and PPG (COF 0.12 ), but did not influence friction in TMP. DBDS had a friction reduction effect for all base oils after rubbing for 2 hours, but initial COFs were higher than that of the base oils. The lowest COF at test end was found with TMP + DBDS combination. The unsaturated TMP-ester +1 mass $\%$ DBDS showed 45\% lower friction in comparison to $\mathrm{PAO}+\mathrm{ZnDTP}$ (reference). Furthermore, a positive effect with regard to friction behavior could also be achieved by oil formulation of PPG + DBDS which showed $30 \%$ lower friction than the reference oil.

\subsection{Tribochemistry of the blended EALs in steel/PEO system}

The anti-wear mechanisms of ZnDTP and DBDS have been studied by many researchers in hydrocarbon base oils, such as mineral oil and PAO for steel/steel tribosystem. Tribochemical reaction will build tribofilms composed of complex reaction products from
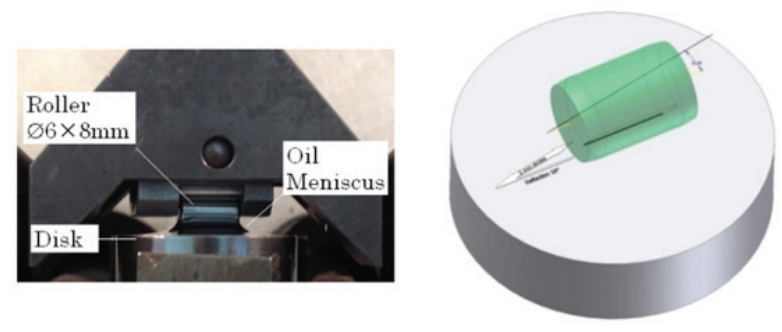

Fig. 2 Standard inclined roller SRV showing oil meniscus 


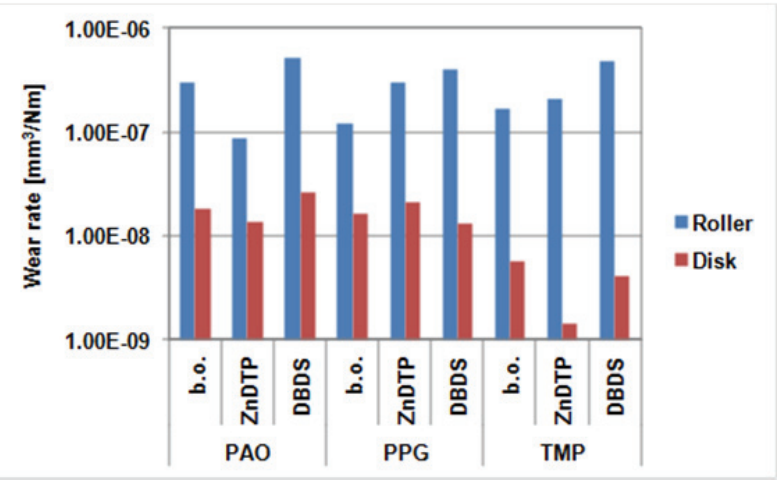

Fig. 3 Wear rates of steel/PEO tribocouples lubricated with different blended oils using DIN 51834-4

additives. The tribofilm will protect the surface and improve wear resistance. In order to produce triboreaction film, additive must initially adsorb onto the surface. When a polar base oil is used as carrier fluid, the base oil and the additive will compete with each other. Consequently, base oils with higher polarity showed different wear and friction behavior by use of steel/PEO in the present study.

Scanning Electron Microscopy/Energy Dispersive X-ray Spectroscopy (SEM/EDX) analysis on wear scar was conducted to understand the mechanism. Tribofilms from ZnDTP can be detected through zinc, phosphorus and sulfur, whereas the metal-free DBDS only through sulfur. These elements are not present either in the tribomaterials or the base oils. Since wear of the disks regardless of the lubricants were very small while wear of rollers were more discriminative, results on wear tracks of all rollers are presented in Fig. 7 to 9, but only typical wear tracks of disk are presented in Fig. 10.

Observing the wear track of the roller lubricated with PAO base oil (Fig. 7(a)), micro-damage and oxidation were detected which can be the evidence of the relative high friction and adhesive wear. This may

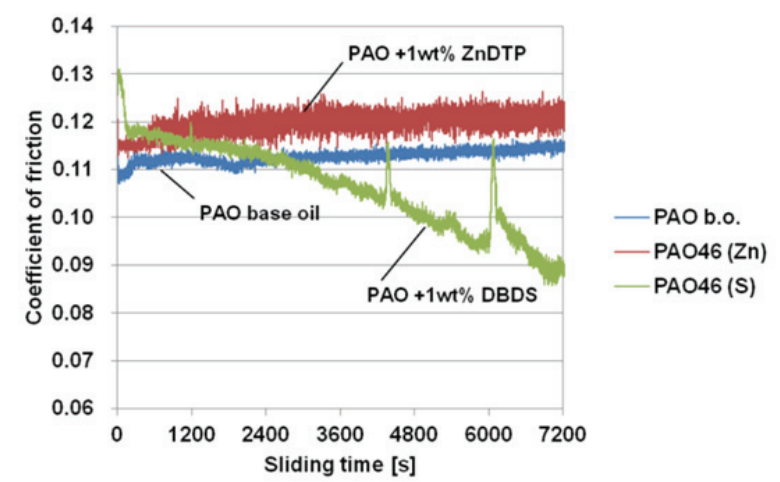

Fig. 4 Coefficient of friction vs. sliding time of steel/PEO lubricated with PAOs

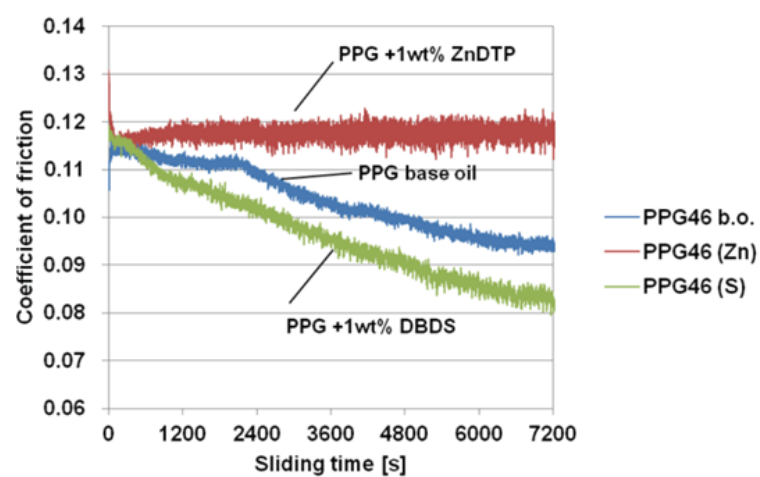

Fig. 5 Coefficient of friction vs. sliding time of steel/PEO lubricated with PPGs

cause seizure when more severe contact condition is applied. The addition of ZnDTP into PAO prevented such micro-damage by tribofilm formation containing $\mathrm{Zn}, \mathrm{P}$ and $\mathrm{O}$, whereby the friction value was at the highest level. Smooth sliding surfaces with sulfur containing film were yielded by PAO blended with 1 mass \% DBDS. Additionally, the friction was reduced.

Due to the higher polarity of PPG and TMP, even base oils were expected to protect the PEO sliding surfaces. Figure 8(a) shows that PPG base oil lubricated the surface better than PAO base oil, as less or no micro-damage was observed on the wear track of the roller. TMP ester provided much smoother sliding surface as shown in Fig. 9(a). For this reason, PPG and TMP are also used as lubricant additives in combination with base oils offering insufficient lubricity.

Both blended PPG oils formed tribofilms, but in contrast to blended TMP less additive elements were found within the wear scar. In Fig. 8(b) shows the EDX spectrum of PPG + ZnDTP oil. Zinc, phosphorus, sulfur and slight oxygen-level were detected nearly in the same range found for PAO $+\mathrm{ZnDTP}$. For PPG+DBDS, a small amount of sulfur was detected.

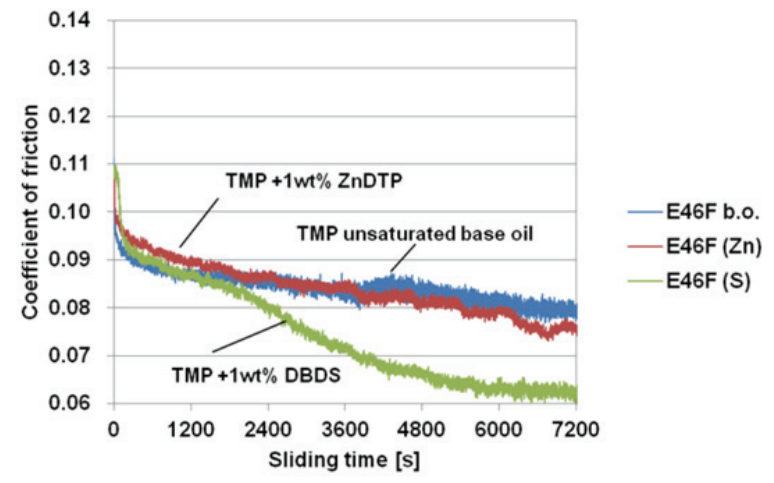

Fig. 6 Coefficient of friction vs. sliding time of steel/PEO lubricated with TMP unsaturated esters 
(a)

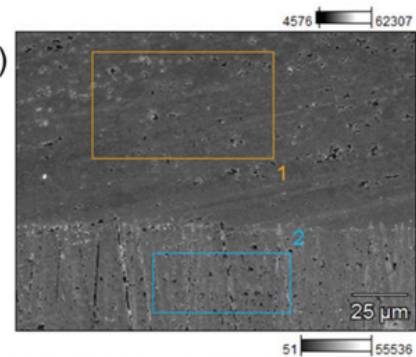

(b)

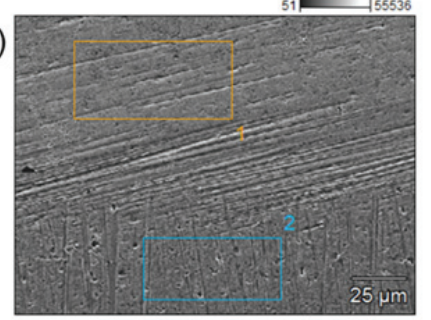

(c)

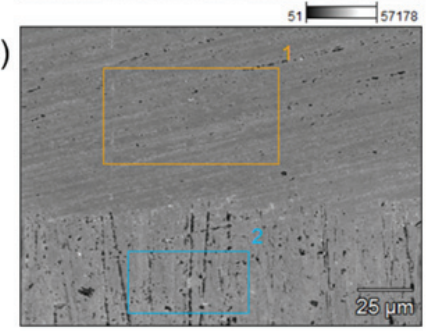

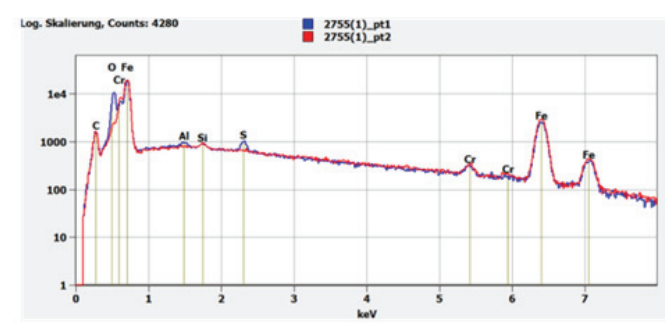

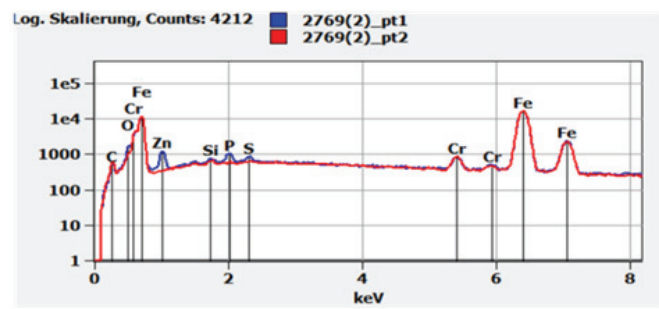

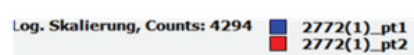

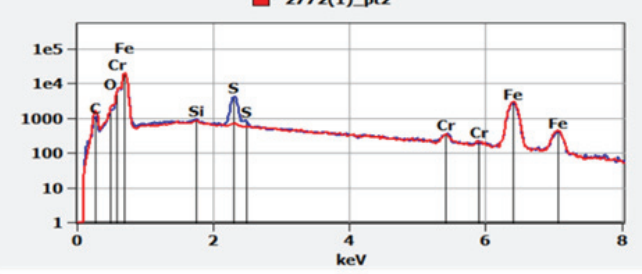

Fig. 7 SEM image and EDX spectrum on 100Cr6 lubricated with PAO blended oils in 100Cr6/PEO; (a) base oil: showing adhesive wear and pits, surface oxidation, (b) +ZnDTP: Zn, P, O and S on wear track and (c) +DBDS: smooth wear, EDX spectrum shows sulfur on wear track

(a)

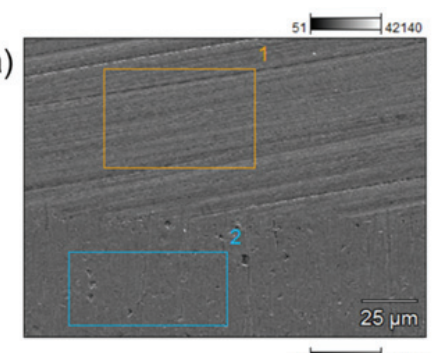

(b)

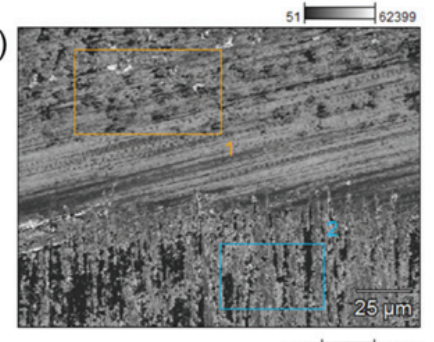

(c)

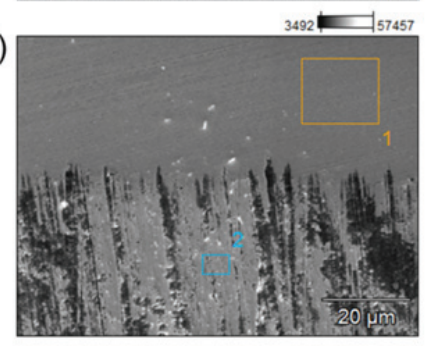

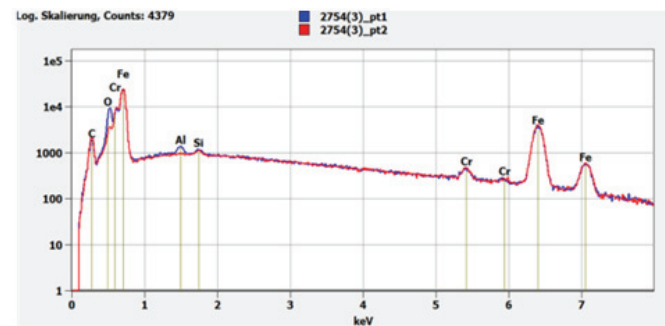
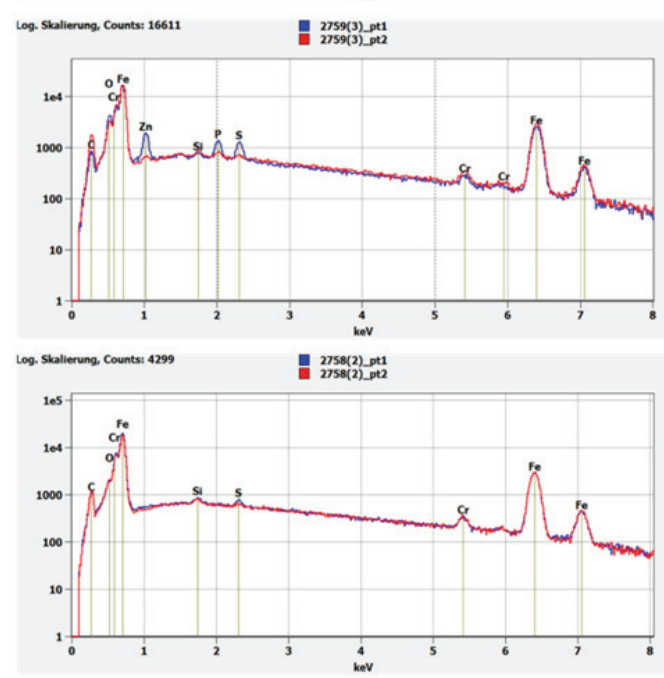

Fig. 8 SEM image and EDX spectrum on 100Cr6 lubricated with PPG blended oils in 100Cr6/PEO; (a) base oil: showing scratches, surface oxidation, (b) +ZnDTP: Zn, P, O and S on wear track and (c) +DBDS: smooth wear, EDX spectrum shows sulfur on wear track 
(a)

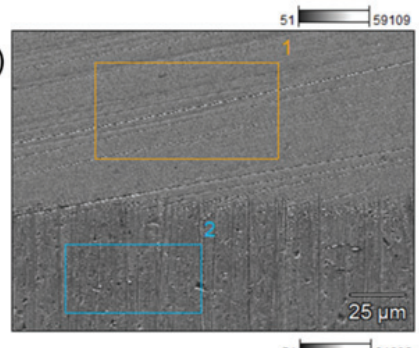

(b)

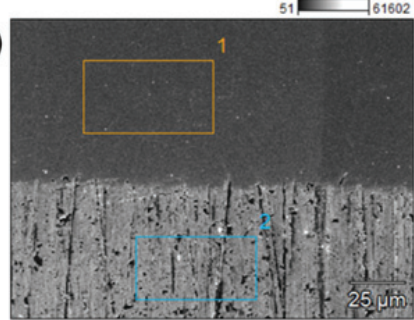

(c)

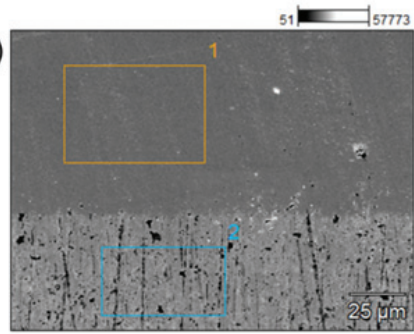

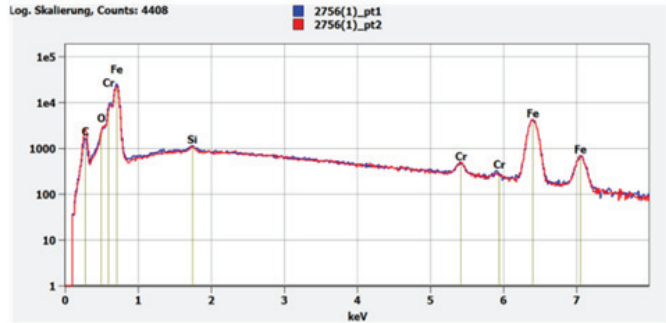
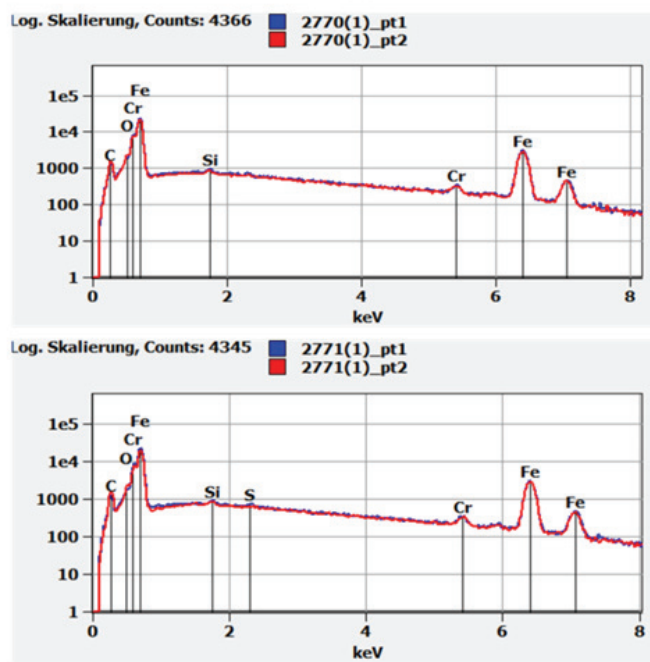

Fig. 9 SEM image and EDX spectrum on 100Cr6 lubricated with TMP unsaturated ester blended oils in 100Cr6/PEO; (a) base oil: showing scratches, no element change, (b) +ZnDTP: smooth wear scar, no element change and (c) +DBDS: smooth wear scar, no element change

(a)

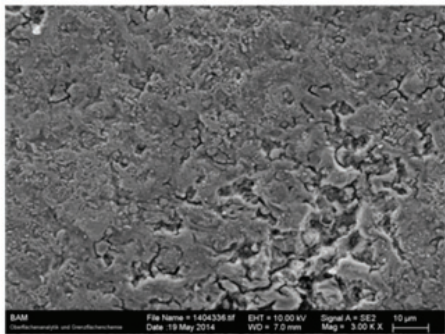

(c)

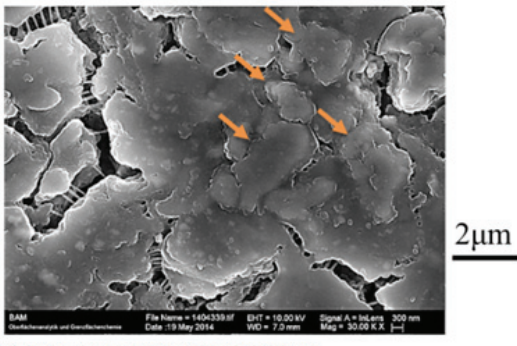

(e)

Stalierung Counts: 24324 2758 Scheibe(2) ont

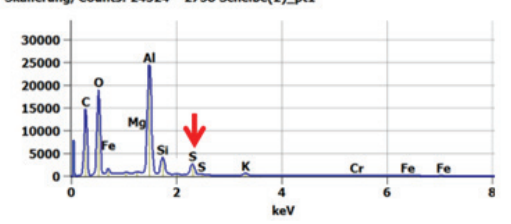

(b)

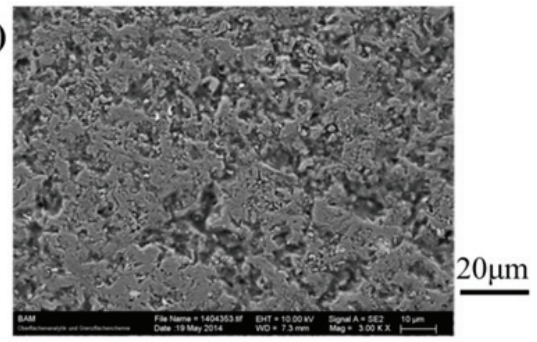

(d)

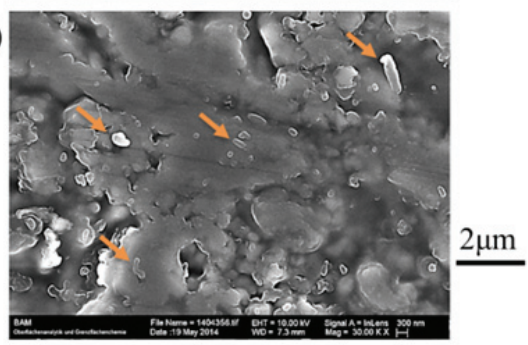

(f)

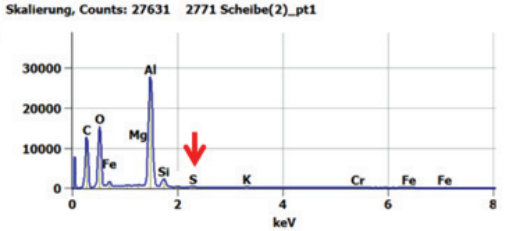

Fig. 10 SEM images of wear tracks of PEO lubricated with (a and c) PPG+DBDS and (b and d) TMP unsaturated ester+DBDS, EDX spectra on PEO disks; e) PPG+DBDS, sulfur and iron were detected on wear scar and f) lubricated with TMP unsaturated ester+DBDS, no sulfur was detected on wear scar 
Considering Fig. 9(b) and (c) it would appear that any tribofilm for two blended TMP was not observed by EDX analysis on the sliding surface of the steel roller. Thus, the TMP base oil probably has very strong interaction onto surface of metal and metal oxide. In terms of wear, TMP ester itself proper lubricated the PEO surface resulting in extremely low wear. Although, PEO coating is composed of alumina and thus it is chemically stable under static condition, it might be able to interact with oil when tribological action is applied [8]. It is known that esters can form antiwear aluminium soap on alumina rubbing surface [9]. Figure 10 compares FE-SEM images of the wear tracks on PEO lubricated with PPG +1 mass $\%$ DBDS and TMP +1 mass $\%$ DBDS. Sulfur and iron were detected for PPG+DBDS, while no sulfur but only small amount of iron was detected for TMP+DBDS. Pad-like tribofilm can be observed for PPG+DBDS as shown in Fig. 10(c) (recognized as relative white contrast arrowed in the image). This might be compounds containing iron and sulfur, as these elements were detected by EDX (Fig. 10(e)). On the other hand, TMP+DBDS did not form such a solid tribofilm, only sub-micron size particles (arrowed in Fig. 10(d)) were observed. These particles might be the soap-like triboreaction products mainly caused by TMP base oil, containing no sulfur (Fig. 10(f)). These films formed on rubbing surface probably reduced the friction.

The low wear and the low COF below 0.08 was observed with TMP blended oils, regardless of the formulation, even no tribofilm was detected by the EDX analysis. These lubrication mechanisms can be explained according to the hard and soft acids and bases (HSAB) principle [10]. PEO coated aluminium alloy (i.e. aluminium oxide) has the hard acid and more likely to bind to hard base molecules rather than neutral and soft base molecules. PAO is non-polar and neutral. PPG and TMP ester are polar and hard bases. Hence, PPG and TMP ester provide better adsorption on to metal oxide surfaces rather than PAO. TMP unsaturated ester has three carbon double bond $(\mathrm{C}=\mathrm{C})$ and three ester bonds (-COO-) in the molecule (Fig. 1). These bonds can be cleaved or oxidized and decomposed product can

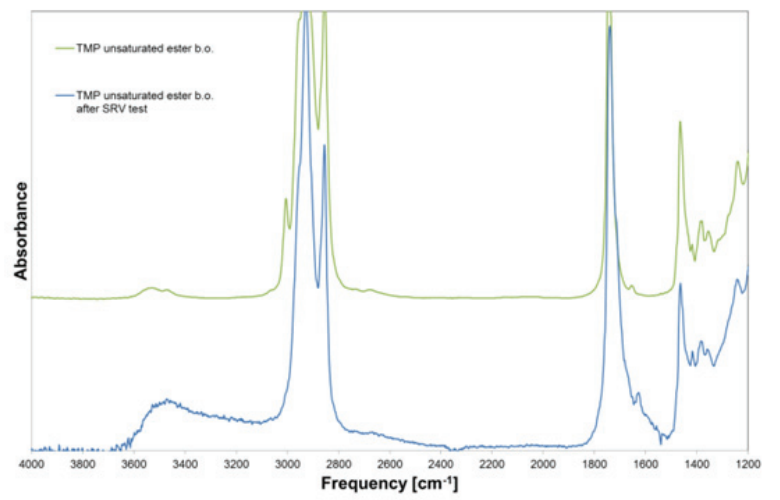

Fig. 11 FTIR spectra of TMP unsaturated ester before and after the sliding test at $80^{\circ} \mathrm{C}$ be polymerized by heat, hydrolysis and tribomechanical stress [11]. Figure 11 shows fourier transform infrared (FTIR) spectra of TMP unsaturated ester before and after the sliding test. Disappearance of the peak at 3004 $\mathrm{cm}^{-1}$ after the test indicates that $\mathrm{C}=\mathrm{C}$ bonds were cleaved or oxidized. Increasing of the broad peak at around $3400 \mathrm{~cm}^{-1}$ perhaps indicates increase of $-\mathrm{OH}$ bond. This means the ester was hydrolyzed and then produced alcohols and carboxylic acids. These decompositions of TMP ester produces more hard bases, in consequence it has stronger adsorbability compared to PPG which is also classified as hard base. After the sliding test using TMP ester, easily shearable polymeric layer was formed on rubbing surface, which may be the organic tribochemical reaction product from the base oil.

Furthermore, it should be considered that producing such decomposed product leads to an aging effect of base oil. It is well known that the higher the degree of unsaturation is, the higher the oxidation rate would be under high temperature condition even without tribological action. So it is necessary to select an appropriate antioxidant for unsaturated esters. Here, DBDS is the soft base molecule. Hard acid is more likely to have stronger interaction with hard bases rather than soft bases. Therefore, TMP+DBDS did not form tribofilm. However, DBDS reduced COF by approx. $25 \%$ for TMP ester probably due to synergistic effect. DBDS also has antioxidation effect for oil [12], so that it reduced the oxidation deterioration, i.e. $\mathrm{C}=\mathrm{C}$ cleavage. Figure 12 shows the IR spectra focused at the peak corresponding to $\mathrm{C}=\mathrm{C}$ bond that comparing fresh TMP ester base oil, the tested base oil and the tested TMP ester+DBDS formulation oil. The peak of $\mathrm{C}=\mathrm{C}$ bond slightly remained after the SRV test by additivation with DBDS. If the carbon double bond remains, the carbon chain length does not change. The longer carbon chain can lubricate sliding surface better than shorter carbon

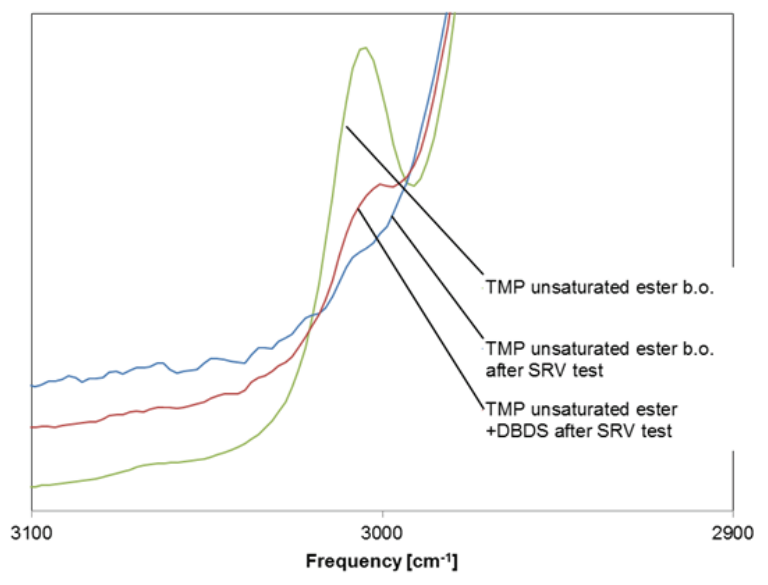

Fig. 12 FTIR spectra focused at the peak corresponding to $\mathrm{C}=\mathrm{C}$ bond that comparing fresh TMP ester base oil, the tested base oil and the tested TMP unsaturated ester+DBDS formulation oil 


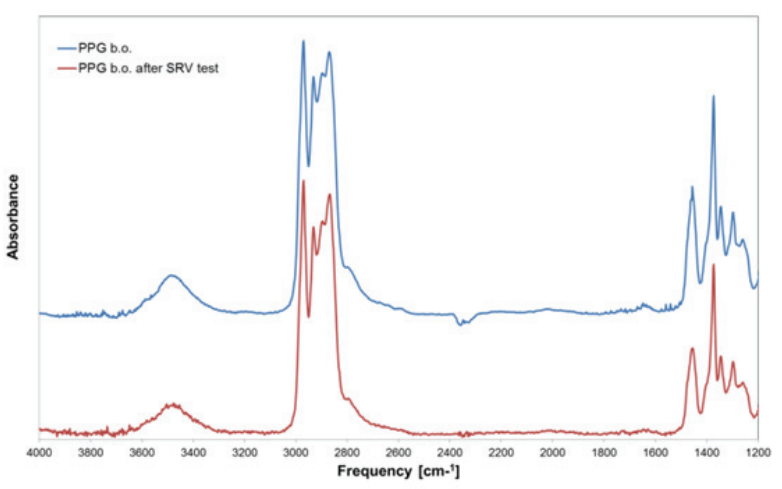

Fig. 13 FTIR spectra of PPG before and after the sliding test at $80^{\circ} \mathrm{C}$

chain under boundary lubrication.

In contrast, PPG did not change its chemical structure as far as analyzed by means of FTIR (Fig. 13). PPG itself can be strongly adsorbed by metal surface without producing new reaction products. The reason for this behavior is an ether link (C-O-C), e.g., an oxygen polarity, contained in each monomer of the whole backbone.

From the discussion above, it was clarified that the adsorption behavior of base oil is important on the friction and wear reduction mechanism thorough combination of HSAB principle and FTIR analysis.

\section{Conclusions}

In this paper, the influence of the tribological property of EALs on the PEO coating was investigated in comparison to hydrocarbon based oil formulation. PAO revealed the highest level of $\mathrm{COF}$ when either base oil or ZnDTP blended PAO was used, whereas DBDS showed friction reduction effect. On the steel rubbing surface with PAO base oil, micro-damage was observed, which the evidence of adhesive wear is. Hydrocarbon-base oil needs to be additivated with antiwear additive to protect sliding surface. On PEO coating sliding against steel, the base oil type significantly influenced the friction and wear behavior, because of the different adsorbability of base oil. The following conclusions can be drawn.

1. PPG and TMP ester base oil had better lubricity than PAO base oil in PEO-steel tribo-system.

2. The additivation of $\mathrm{ZnDTP}$ made ineffective of the lubricity of PPG due to tribofilm derived from ZnDTP having high friction as PAO $+Z n D T P$. However, for TMP ester the additivation of ZnDTP did not raise the friction.

3. Organic sulfur containing additive DBDS reduced the friction for PPG by forming sulfur containing solid tribofilm on PEO. TMP ester also did not form tribofilm but the friction was reduced.

\section{References}

[1] Spikes, H., "The History and Mechanisms of ZDDP," Tribology Letters, 17, 3, 2004, 469-489.

[2] Lämmle, P. and Rohrbach, P., "Application of ECLs and Today's Legislation,” Journal of ASTM International, 9, 1, 2012, paper ID JAI103563.

[3] Woydt, M., "Biolubrifiants (Biolubes)," Encyclopédie Techniques de l'Ingénieur, Paris, 2014, TRI 1 800v2, 1-12, ISBN 978-2-85059-309-3 (in French).

[4] Woydt, M., "Polyalkylene Glycols as Next Generation Engine Oils," Journal of ASTM International, 8, 6, 2011, paper ID JAI103368.

[5] Konishi, T., Klaus, E. E. and Duda, J. L., "Wear Characteristics of Aluminum-Silicon Alloy under Lubricated Sliding Conditions," Tribology Transactions 39, 4, 1996, 811-818.

[6] Konishi, T. and Perez, J. M., "Properties of Polyol Esters-Lubrication of an Aluminum Silicon Alloy," Tribology Transactions, 40, 3, 1997, 500-506.

[7] Yerokhin, A. L., Shatrov, A., Samsonov, V., Shashkov, P., Pilkington, A., Leyland, A. and Matthews, A. "Oxide Ceramic Coatings on Aluminium Alloys Produced by a Pulsed Bipolar Plasma Electrolytic Oxidation Process," Surface and Coatings Technology, 199, 2-3, 2005, 150-157.

[8] Sasaki, S., "Effects of Environment on Friction and Wear of Ceramics," Bulletin of Mechanical Engineering Laboratory Japan, 58, 1992, 1-109, ISSN: 0374-2725.

[9] Tripathy, B. S., Furey, M. J. and Kajdas, C., "Mechanism of Wear Reduction of Alumina by Tribopolymerization," Wear, 181-183, 1, 1995, 138-147.

[10] Pearson, R. G., "Hard and Soft Acids and Bases," Journal of the American Chemical Society, 85, 22, 1963, 3533-3539.

[11] Totten, G. E. and Liang, H. (Eds.), "Surface Modification and Mechanisms: Friction, Stress, and Reaction Engineering," CRC Press, 2004, 99.

[12] Bridgewater, A. J. and Sexton, M. D., "Mechanism of Antioxidant Action: Reactions of Alkyl and Aryl Sulphides with Hydroperoxides," Journal of the Chemical Society, Perkin Transactions, 2, 6, 1978, 530-536. 